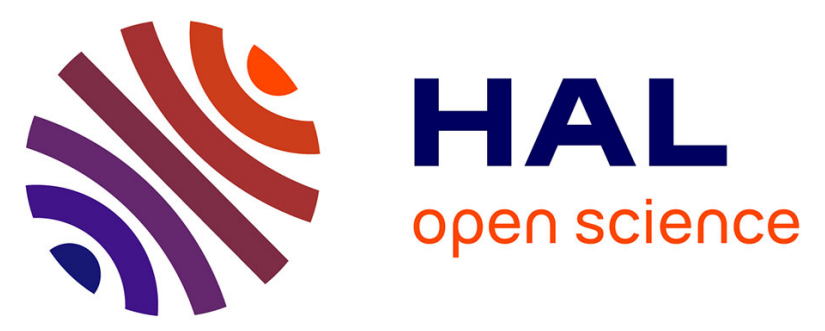

\title{
Development and application of a novel electrochemical immunosensor for tetracycline screening in honey using a fully integrated electrochemical Bio-MEMS
}

Nadia El Alami El Hassani, Abdoullatif Baraket, Selim Boudjaoui, Ernandes Taveira Tenório Neto, Joan Bausells, Nezha El Bari, Benachir Bouchikhi, Abdelhamid Elaissari, Abdelhamid Errachid, Nadia Zine

\section{To cite this version:}

Nadia El Alami El Hassani, Abdoullatif Baraket, Selim Boudjaoui, Ernandes Taveira Tenório Neto, Joan Bausells, et al.. Development and application of a novel electrochemical immunosensor for tetracycline screening in honey using a fully integrated electrochemical Bio-MEMS. Biosensors and Bioelectronics, 2019, 130, pp.330-337. 10.1016/j.bios.2018.09.052 . hal-02092892

\section{HAL Id: hal-02092892 \\ https://hal.science/hal-02092892}

Submitted on 22 Oct 2021

HAL is a multi-disciplinary open access archive for the deposit and dissemination of scientific research documents, whether they are published or not. The documents may come from teaching and research institutions in France or abroad, or from public or private research centers.
L'archive ouverte pluridisciplinaire HAL, est destinée au dépôt et à la diffusion de documents scientifiques de niveau recherche, publiés ou non, émanant des établissements d'enseignement et de recherche français ou étrangers, des laboratoires publics ou privés.

\section{다)(1) $(5$}

Distributed under a Creative Commons Attribution - NonCommerciall 4.0 International 
 \\ Development and application of a novel electrochemical immunosensor for tetracycline screening in honey using a fully integrated electrochemical Bio- MEMS
}

Nadia El Alami El Hassani ${ }^{\text {a,b,c }}$, Abdoullatif Baraket ${ }^{c}$, Selim Boudjaoui ${ }^{c}$, Ernandes Taveira Tenório Neto ${ }^{\mathrm{d}}$, Joan Bausells ${ }^{\mathrm{e}}$, Nezha El Bari ${ }^{\mathrm{a}}$, Benachir Bouchikhi ${ }^{\mathrm{b}}$, Abdelhamid Elaissari d, Abdelhamid Errachid ${ }^{\mathrm{c}}$, Nadia Zine ${ }^{\mathrm{c}^{*}}$

${ }^{a}$ Biotechnology Agroalimentary and Biomedical Analysis Group, Department of Biology, Faculty of Sciences, Moulay Ismaïl University, BP 11201, Zitoune, Meknes, Morocco.

${ }^{\mathrm{b}}$ Sensor Electronic and Instrumentation Group, Department of Physics, Faculty of Sciences, Moulay Ismail University, BP 11201, Zitoune, Meknes, Morocco.

${ }^{\mathrm{c}}$ Université de Lyon, Institut des Sciences Analytiques, UMR 5280, CNRS, Université Lyon 1, ENS Lyon - 5, rue de la Doua, F-69100 Villeurbanne, France.

${ }^{\mathrm{d}}$ Université de Lyon, LAGEP, UMR-5007, CNRS, Université Lyon 1, 5007, 43 Bd 11 Novembre 1918, F-69622 Villeurbanne, France.

e Instituto de Microelectronica de Barcelona, IMB-CNM (CSIC) Campus UAB, 08193, Bellaterra, Barcelona, Spain.

*Corresponding author: E-mail address: nadia.zine@univ-lyon1.fr

\begin{abstract}
:
Tetracycline (TC) is a veterinary drug, wildly prescribed for prophylactic and therapeutic purposes. Consequently, its remaining residues in food products have to be regularized. We report in this paper about the development of a novel immunosensor based on an integrated bio micro-electromechanical system (Bio-MEMS) containing eight gold microelectrodes ( $\mu$ WEs), an integrated silver and platinum reference and counter electrodes, respectively. TC immobilization on the $\mu$ WEs surface was conducted using three methods. The first through functionalization with 4-aminophenylacetic acid (CMA), the second by functionalization with CMA followed by preconcentration of a new structure of magnetic nanoparticles (MNPs) coated with poly (pyrrole-co-pyrrole-2-carboxylic acid) (Py/Py-COOH/MNPs) cross-linked with $\mathrm{Ab}-\mathrm{TC}$, and the last one directly through the functionalization with $\mathrm{Py} / \mathrm{Py}-\mathrm{COOH} / \mathrm{MNPs}$. The analyte was quantified by competitive detection with TC immobilized on the $\mu$ WEs surface toward specific polyclonal antibody (Ab-TC), using a mixture of a fixed concentration of $\mathrm{Ab}$-TC and decreasing levels of TC one from $0.1 \mathrm{pg} \cdot \mathrm{mL}^{-1}$ to $1000 \mathrm{pg} \cdot \mathrm{mL}^{-1}$. Microcontact printing, followed by fluorescence microscopy characterization were performed during the functionalization of the immunosensor surface to certify that the corresponding immune detection process is taking place. This immunosensor was found to be highly sensitive with a limit of detection of $1.2 \mathrm{pg} . \mathrm{mL}^{-1}$ and specific in the presence of interferents. The standard addition method was exploited to detect TC in honey samples. The present immunosensor platform is up-and-coming for TC detection which can dramatically decrease the time of analysis providing a new pathway for advanced immunoassays development in industrial food control.
\end{abstract}

\section{Keywords:}

Bio-MEMS, Magnetic nanoparticles (MNPs), Immunosensor, Soft lithography, micro contact printing, Food control. 


\section{Introduction}

Tetracycline (TC) is a broad-spectrum antibiotic used as a veterinary drug to prevent and to treat diseases caused by Gram-positive and Gram-negative bacteria, atypical organisms such as Chlamydiae, Mycoplasmas, Rickettsia, and protozoan parasites (Eliopoulos et al., 2003). The favorable antimicrobial properties of this drug and the absence of significant adverse side effects have led to their extensive use in the therapy of both human and animal infections (Chopra and Roberts, 2001). Furthermore, it has been reported as the most intensely growth-promoting agent widely used in animal husbandry (Economou and Gousia, 2015). Consequently, despite their proven efficacy, the intensive use of this drug is no longer encouraged since its remain residues can be accumulated in the animal bones, as well as in fish, meat, eggs, and milk, on account of the complexation of TC with $\mathrm{Ca}^{2+}$ (Nelson et al., 2010). To ensure human food safety, the European Union (EU) has established the maximum residue limits (MRLs) for TC in edible products and milk at $100 \mu \mathrm{g} \cdot \mathrm{kg}^{-1}$, in eggs at $200 \mu \mathrm{g} \cdot \mathrm{kg}^{-1}$ and in the liver at $300 \mu \mathrm{g} \cdot \mathrm{kg}^{-1}$ (European Commission, 1999). However, the MRLs for TCs in honey has not yet been established by Codex, since the treatment of honeybee diseases with antibiotics is unallowable in the EU (Kivrak et al., 2016). Despite banning, some countries, such as Switzerland, UK, and Belgium still use TC treatment for hive diseases and have established, therefore, the MRLs for TC ranging from 10 to $50 \mu \mathrm{g} . \mathrm{kg}^{-1}$ (Bargańska et al., 2011).

However, TC residues can be successfully determined in various food products requiring highly performing sample preparation steps. Several analytical methods currently exist for TC detection and quantification. High performance liquid chromatography coupled to mass spectrometry (Pokrant et al., 2018), capillary electrophoresis coupled with electrochemiluminescence (Deng et al., 2012), enzyme immunoassay (Gaurav et al., 2014), liquid chromatography-mass spectroscopy (LC-MS) (Desmarchelier et al., 2018) have been described for confirmatory analysis. Other methodologies based on spectroscopy analysis are described (Qin et al., 2016); unfortunately, they suffer from a lack of sensitivity compared to chromatographic techniques (Mitra, 2004). Subsequently, Most of these approaches often require the use of extraction techniques, such as liquid-liquid (Desmarchelier et al., 2018) and solid phase extraction (Shi et al., 2011), in order to accomplish both the analytes preconcentration and sample cleanup (O'Connor and Aga, 2007). However, the principal limitations of these steps lie in the high costs, the long time of achievement and the requirement of advanced technical skills (Joshi and Anderson, 2012). For this reason, simple, rapid and accurate methods are recommended for the on-site screening of low TC residues without needing extraction or clean-up steps. Due to their advantages of high selectivity, rapid detection, and in-situ applications, several optical and electrochemical techniques based on biosensors have been investigated (Lan et al., 2017). Therefore, aptamer-based sensing techniques were widely used for the food safety determination. Notably, there is a growing rise in the aptasensors fabrication for the TC detection (Han et al., 2018; Tang et al., 2017) with a few applications in honey samples (Wang et al., 2015, 2014). Nevertheless, the main limitations of these systems are related to their relative low detection signals (Yi et al., 2014). Furthermore, in some recent works, the molecularly imprinted sensors had been successfully applied to the analysis of antibiotic residues in honey samples (Bougrini et al., 2016; Lv et al., 2014). This type of sensors, however, often show relatively low sensitivity and specificity when the imprinted membrane is fragile. Hence, on the last few decades, the development of immunosensors grew tremendously to the detection of drug residues in food. The use of these analytical systems has attracted considerable attention because of the low detection limits and the high selectivity for analyzing complex samples (Majdinasab et al., 2017). In this regard, some immunosensors were performed for TC detection in milk samples (Conzuelo et al., 
2013; Liu et al., 2016) with the limits of detection being $0.032,3.9$, and $0.85 \mathrm{ng} \cdot \mathrm{mL}^{-1}$, respectively.

Herein, a novel and highly sensitive approach is proposed for the detection of remaining TC residues in honey samples. This immunosensor was conducted on bio-microelectro-mechanical systems (Bio-MEMS) transducers based on gold micro working electrodes ( $\mu$ WEs) with fully integrated, reference and counter electrodes. The novelty of this work is related to the functionalization process of $\mu \mathrm{WEs}$, which was achieved through two- and threedimensional (2D and 3D) shapes. These functionalizations were conducted, in one hand, by electroaddressing diazonium salt and, in the other hand, by electrodepositing of a new structure of magnetic nanoparticles coated poly(pyrrole-co-carboxylic acid) (Py/Py$\mathrm{COOH} / \mathrm{MNPs}$ ), while combining the two methods with a preconcentration technique. The $\mathrm{Py} / \mathrm{Py}-\mathrm{COOH} / \mathrm{MNPs}$ as solid supports of biomolecules, is the pioneering aspect of this work dedicated to the combination of submicron, magnetic conducting particles. The quantification of this analyte was performed through competitive detection procedure with TC molecules immobilized on the $\mu$ WEs surface toward polyclonal TC antibody. The prepared immunosensor was successfully applied to enhance the detection limit of TC in complex matrices such as honey.

\section{Experimental}

\subsection{Reagents and solutions}

Tetracycline (TC), Doxycycline (DX), Oxytetracycline (OX), Chlortetracycline (CT), 1-Ethyl-3-(3-dimethylaminopropyl)carbodiimide (EDC), Ethanolamine, Sulfuric acid $\left(\mathrm{H}_{2} \mathrm{SO}_{4}\right)$ (30 wt.\% in $\left.\mathrm{H}_{2} \mathrm{O}\right)$, 4-aminophenylacetic acid (CMA), sodium nitrite $\left(\mathrm{NaNO}_{2}\right)$, Sodium cyanoborohydride $(95 \%)$, hydrochloric acid $(37 \%, \mathrm{HCl})$, Carbon tetrachloride, heptane, octadecyltrichlorosilane (OTS), Pure ethanol (99.8\%), Acetone (99.9\%), Potassium hexacyanoferrate II, Potassium hexacyanoferrate III, Phosphate buffer saline (PBS) with $\mathrm{pH}$ 7.4 were all purchased from Sigma-Aldrich, France. N-Hydroxysuccinimide (NHS) and Hydrogen peroxide $\left(\mathrm{H}_{2} \mathrm{O}_{2}\right)(35 \%$, v/v) were purchased from Acros Organics, France. 11(triethoxysilyl)undecanal (TESUD) was purchased from abcr GmbH, Germany. Polydimethylsiloxane (PDMS: Sylgard 184) was purchased from Dow Corning, France. The sheep polyclonal antibody raised against TC (Ab-TC) was supplied by Abcam, France. A fluorescent labeled antibody was generated by conjugation of Ab-TC with rhodamine using the rhodamine fast conjugation kit (ab188286) by Abcam, France. Rosemary honey sample, guaranteed tetracycline-free was supplied by Secrets d'Apiculteur, Lyon, France. Honey sample with an unknown concentration of TC was commercially provided. Milli-Q ultrapure water was used in all experiments.

\subsection{Procedure for immunosensor elaboration}

The development of this immunosensor was conducted by three methods (Fig. 1). Before any functionalization, the Bio-MEMS device surface was cleaned with ethanol in an ultrasonic bath for $10 \mathrm{~min}$, dried under nitrogen flow, then placed under UV-Ozone CleanerProCleaner ${ }^{\mathrm{TM}}$ Plus from BioForce for 30 min to remove all organic contaminants. 


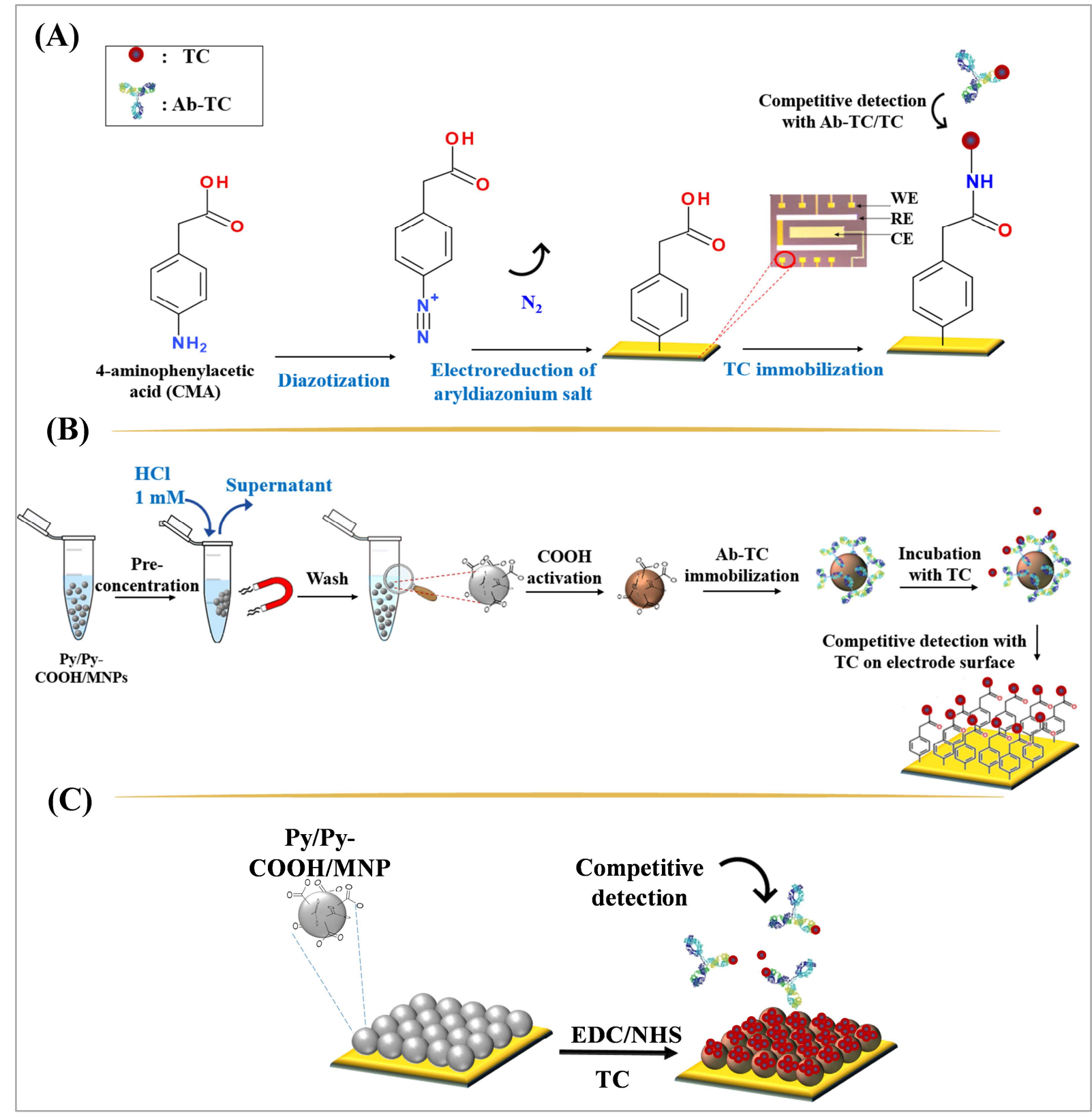

Fig.1. Schematic illustrations of competitive immunoassay of TC on modified $\mu$ WEs by functionalization with: (A) CMA electroaddressing, (B) CMA electroaddressing followed by preconcentration of immunomagnetic nanoparticles cross-linked with Ab-TC antibody, (C) $\mathrm{Py} / \mathrm{Py}-\mathrm{COOH} / \mathrm{MNPs}$.

\subsubsection{Diazonium immobilization onto gold microelectrodes}

The cleaned microelectrodes ( $\mu \mathrm{WEs}$ ) were functionalized by CMA solution $(3 \mathrm{mM})$ previously diazotized in an aqueous solution of $\mathrm{HCl}(20 \mathrm{mM})$ and $\mathrm{NaNO}_{2}(20 \mathrm{mM})$ for 15 min at $4{ }^{\circ} \mathrm{C}$. Subsequently, nine-repetitive cyclic voltammograms were applied from $0.3 \mathrm{~V}$ to $-1.0 \mathrm{~V}$ with a scan rate of $80 \mathrm{mV} . \mathrm{s}^{-1}$. This was done sequentially until all desired $\mu \mathrm{WEs}$ were modified with CMA. The carboxylic groups formed on the electrode surfaces were activated by a mixture of $0.4 \mathrm{M}$ EDC and 0.1 M NHS, prepared in ethanol for one hour at room temperature. Afterwards, the activated electrode surfaces were incubated in $40 \mu \mathrm{L}$ of TC at $100 \mu \mathrm{g} \cdot \mathrm{mL}^{-1}$ for $30 \mathrm{~min}$ at $4{ }^{\circ} \mathrm{C}$. Then, the immunosensor was treated with ethanolamine $(1 \%$ $\mathrm{v} / \mathrm{v}$ ) in PBS buffer ( $\mathrm{pH}$ 7.4) for $10 \mathrm{~min}$ at room temperature. This step is crucial to prevent nonspecific bonding phenomenon at the detection stage of TC (Fig. 1A). 


\subsubsection{Preconcentrating technique}

The core-shell magnetic nanoparticles coated with poly(pyrrole-co-pyrrole carboxylic acid) (Py/Py-COOH/MNPs) were exclusively synthesized by (Tenório-Neto et al., 2016) using a seeded-polymerization technique. The morphology of these nanoparticles was already presented in our previous work (Hassani et al., 2017) using transmission electron microscopy (TEM). Here, the magnetic nanoparticles stock solution $(100 \mu \mathrm{L})$ was washed three times with PBS buffer ( $\mathrm{pH}$ 7.4) in a magnetic field to separate the nanoparticles from the storage solution. EDC and NHS solutions (each at a concentration of $100 \mathrm{mM}$ ) were prepared immediately before use. A volume of $250 \mu \mathrm{L}$ each of EDC and NHS solutions were added to the washed magnetic nanoparticles and incubated with slow rotation at room temperature for $90 \mathrm{~min}$. Then, the reaction mixture was rinsed three times with $\mathrm{HCl}(1 \mathrm{mM})$ at $4{ }^{\circ} \mathrm{C}$ in a magnetic field. Subsequently, $100 \mu \mathrm{L}$ of purified Ab-TC polyclonal antibody $\left(100 \mu \mathrm{g} \cdot \mathrm{mL}^{-1}\right)$ was added to the activated nanoparticles and incubated for $2 \mathrm{~h}$ at $4{ }^{\circ} \mathrm{C}$. The antibody-coated nanoparticles were washed three times with PBS buffer ( $\mathrm{pH}$ 7.4). The non-reacted activated carboxylic acid groups were blocked with ethanolamine (1\% v/v) in PBS buffer for $10 \mathrm{~min}$. The antibody-coated magnetic nanoparticles were then separated from the mixture, resuspended in $500 \mu \mathrm{L}$ of PBS buffer and incubated with different concentrations of TC (Fig. 1B). Simultaneously, the gold $\mu$ WEs were functionalized by CMA and TC as described in paragraph 2.2.1.

\subsubsection{Functionalization with $\mathrm{Py} / \mathrm{Py}-\mathrm{COOH} / \mathrm{MNPs}$}

This functionalization was performed by electrodepositing Py/Py-COOH/MNPs onto microelectrodes by using pulsed chronoamperometric technique (PCA). Briefly, two continuous repetition potentials were applied: the first potential $E_{1}=-0.2 \mathrm{~V}$ for $t_{1}=0.1 \mathrm{~s}$, induces a cathodic electrodeposition process, while the second potential $\mathrm{E}_{2}=0.2 \mathrm{~V}$ for $\mathrm{t}_{2}=0.1 \mathrm{~s}$ oxidizes the electrode surface, and in particular, cleans it from eventual extraneous deposited species. The cycling process was iterated 30 times. Then, the gold $\mu \mathrm{WEs}$ were rinsed with distilled water. Besides, it is interesting to point out that the amplitude of the charge-discharge process remains practically unchanged during the prolonged cycling process, indicating that the electrode surface exhibits a homogenous Py/Py-COOH/MNPs deposition. The activation of carboxylic groups, present in the Py/Py-COOH/MNPs, was carried out by the mixture of EDC/NHS $(0.4 \mathrm{M} / 0.1 \mathrm{M})$ prepared as described above. The biofunctionalization and blocking steps were performed by incubating the sensor in TC solution $\left(100 \mu \mathrm{g} \cdot \mathrm{mL}^{-1}\right)$ and ethanolamine/PBS (1\% v/v), respectively. Finally, the immunosensor was rinsed with PBS and used for TC detection (Fig. 1C). The homogeneity and the roughness of the resulted $\mu$ WEs surface were already examined in our preceding study (Hassani et al., 2017). This was conducted by two-, and three-dimensional surface topography using atomic force microscopy (AFM). The interest of using this technique is to ensure that the $\mu \mathrm{WE}$ surfaces were entirely homogeneous with the presence of spherical shapes indicating the presence of MNPs coated with $\mathrm{Py} / \mathrm{Py}-\mathrm{COOH}$.

\subsection{Micro-contact printing}

The soft-lithographical technique called microcontact printing $(\mu \mathrm{CP})$ of selfassembled monolayers (SAMs) was employed to check the immune TC/Ab-TC reactivity. For this purpose, an elastomeric stamp based on polydimethylsiloxane (PDMS) was fabricated by replica molding (RM) as already described in previous work (Baraket et al., 2013) . A mixture of pre-polymer PDMS and curing agent $(10: 1 \mathrm{w} / \mathrm{w})$ was poured onto a silanized silicon-mold which contains micro-pillars on relief of its surface (Fig. 2a). Subsequently, complete degassing of PDMS/silanized silicon-mold was carried out to ensure that all air bubbles which may create defects on the PDMS stamp surface have been removed (Fig. 2b). After the polymerization step at $52{ }^{\circ} \mathrm{C}$ for 1 hour, the PDMS stamp was peeled-off from the silicon 
mold bearing the micro holes on its surface (Fig. 2c). The stamp was then inked by immersion for $1 \mathrm{~min}$ in heptane solution containing octadecyltrichlorosilane (OTS) $(0.1 \%, \mathrm{v} / \mathrm{v})$ and carbon tetrachloride $(2 \%, v / v)$, then dried with a stream of nitrogen (Fig. 2d). Simultaneously, glass substrates were cleaned with acetone then ethanol, rinsed with distilled water and then dried with nitrogen. The substrates were activated by submersion in piranha solution $(3: 1 \mathrm{v} / \mathrm{v}$ of $\mathrm{H}_{2} \mathrm{SO}_{4}: \mathrm{H}_{2} \mathrm{O}_{2}$ ) for 30 min then thoroughly rinsed with distilled water and dried with nitrogen. Afterwards, the $\mu \mathrm{CP}$ was realized by putting the prepared PDMS stamp in immediate and conformal contact with a freshly activated glass substrate (Fig. 2e). The PDMS stamp was peeled-off from the substrate, leaving then the SAMs of OTS on the glass surface which was incubated afterwards at $100{ }^{\circ} \mathrm{C}$ for $45 \mathrm{~min}$ to enhance OTS adhesion.

The freshly prepared substrates were submerged in an ethanol solution containing $1 \%$ of TESUD, rinsed with ethanol, dried with a stream of nitrogen and then heated in a vacuum stove at $100{ }^{\circ} \mathrm{C}$ for $60 \mathrm{~min}$ to complete the silanization process (Fig. 2f). Subsequently, the functionalized substrate surface (FSS) was incubated in $250 \mu \mathrm{L}$ of Ab-TC antibody (10 $\mu \mathrm{g} \cdot \mathrm{mL}^{-1}$ ) already diluted in $4 \mathrm{mM}$ of sodium cyanoborohydride. The use of this reagent was conducted to avoid adversely reducing aldehydes to nonreactive hydroxyls, allowing covalent bonding of Ab-TC with the amine of TESUD (Fig. 2g). After that, the FSS were incubated in TC solution ( $\left.0.1 \mathrm{pg} \cdot \mathrm{ml}^{-1}\right)$ for $1 \mathrm{~h}$ to allow the antibody-antigen interaction followed by rinsing in PBS and drying under nitrogen (Fig. 2h). Finally, the rhodamine-labeled polyclonal Ab$\mathrm{TC}^{*}\left(10 \mu \mathrm{g} \cdot \mathrm{ml}^{-1}\right)$ were dropped on the FSS for $1 \mathrm{~h}$ (Fig. $\left.2 \mathrm{i}\right)$. The samples were then rinsed in PBS, dried under nitrogen and observed by fluorescence microscopy.

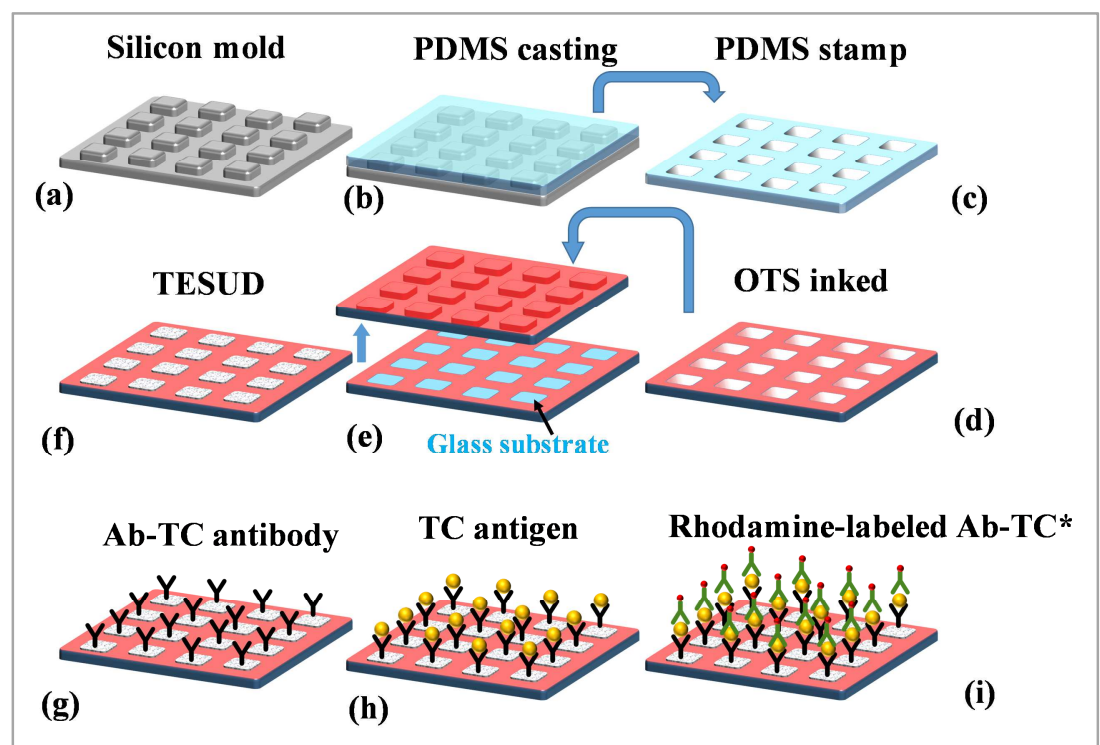

Fig. 2. Microcontact printing process to immobilize Ab-TC onto TESUD patterns and sandwich immunoassay with TC and rhodamine-labeled Ab-TC.

\subsection{Fluorescence microscopy characterization}

Fluorescence images, as a rapid tool showing the recognition of Ab-TC for its corresponding antigen (TC), were taken using a fluorescence microscope (Zeiss Axioplan 2 Imaging), equipped with $10 \times$ and $40 \times$ lenses and a monochrome camera. Samples were observed by fluorescent light: TC sample was excited with a $550( \pm 25) \mathrm{nm}$ band-pass filter and fluorescence from the sample was observed with a $605( \pm 70) \mathrm{nm}$ band-pass filter.

\subsection{Electrochemical measurements}

All steps of gold $\mu$ WEs modification were characterized by cyclic voltammetry (CV) and electrochemical impedance spectroscopy (EIS) techniques using a multi-channel 
potentiostat (VMP3 Bio-logic-Science Instrumentation, France). The electrochemical configuration was performed by using integrated $\mu \mathrm{WEs}, \mathrm{RE}$ and CE of the Bio-MEMS. All the measurements were performed in a solution of $5.0 \mathrm{mM}\left[\mathrm{Fe}(\mathrm{CN})_{6}\right]^{3-/ 4-}$ prepared in PBS buffer ( $\mathrm{pH} 7.4)$ and in a Faraday cage. For the cyclic voltammetric measurements, the potential was scanned from $0.3 \mathrm{~V}$ to $0.6 \mathrm{~V}$ with a scan rate of $100 \mathrm{mV} \cdot \mathrm{s}^{-1}$. While the electrochemical impedance was measured in the $150 \mathrm{mHz}-200 \mathrm{kHz}$ frequency range with a DC potential of $-0.3 \mathrm{~V} / \mathrm{ref}$ and an $\mathrm{AC}$ potential of $90 \mathrm{mV}$.

\section{Results and discussion}

\subsection{Fluorescence analysis}

Fluorescent imaging is considered as an effective tool for bio-functionalization analysis. It's used to certify that the corresponding immune detection process is taking place based upon the recognition of the antibody for its corresponding antigen. In this study, fluorescent antibodies were immobilized (chemically) onto a glass substrate for the detection of TC antigens. Fig. 3A-B shows the fluorescent pattern of $\mathrm{Ab}-\mathrm{TC}^{* \mathrm{R}}$. The red fluorescent regions indicate tags in which the antibodies are specifically immobilized, while the extinct areas are those blocked with OTS. In the Fig.3C, we notice an absence of fluorescence due to the non-cross-reactivity of the doxycycline (DX), as interfering molecules, towards Ab-TC. This immuno-fluorescent test has reported the strong reactivity of Ab-TC against TC which can, therefore, be applied for immunosensor development.
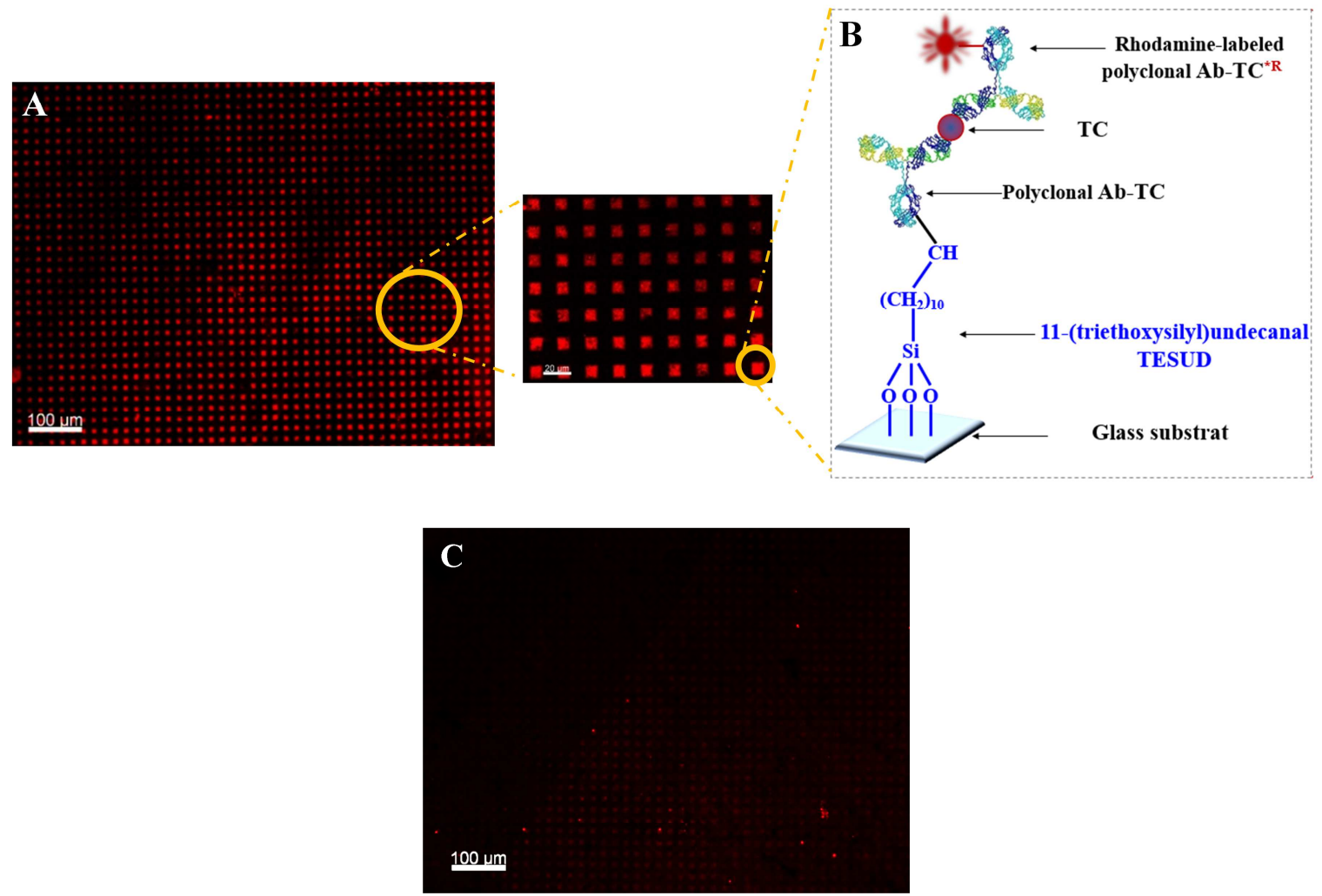

Fig. 3. Fluorescent images of $\left(\mathrm{Ab}-\mathrm{TC}^{* \mathrm{R}}\right)$ chemically immobilized on glass substrates after recognition of $\mathrm{TC}$, (A) Positive homogenous pattern with the blackened regions corresponding to the OTS blocked glass surface. (B) Magnification of the positive pattern showing specific detection between $\mathrm{Ab}-\mathrm{TC}^{* \mathrm{R}}$ and TC. (C) Fluorescent image of the biorecognition assay between doxycycline and $\mathrm{Ab}-\mathrm{TC}^{* \mathrm{R}}$.

\subsection{Electrochemical characterization of modified gold $\mu$ WEs}


The behaviors of CMA and Py/Py-COOH/MNPs films were checked for each step of the Bio-MEMS functionalization by $\mathrm{CV}$ analysis. The process of CMA electro-addressing is shown in Fig. S1A (Supplementary information). The initial cycle shows a large and irreversible cathodic wave with a peak potential at $-0.8 \mathrm{~V}$ revealing diazotated CMA onto the gold $\mu$ WEs surface by diazonium salt reduction. However, the reduction wave has been kept unchanged upon the deposition of CMA. This functionalization was checked by variation of the CV before and after gold $\mu$ WEs modification (Fig. S1B) (Supplementary information). In this figure, a significant decrease in peak-to-peak of the CV cycles was noticed after CMA electro-deposition against the bare gold $\mu$ WEs. This was referred to the broad passivation region of this microelectrodes.

While Fig. S1C (Supplementary information) shows the chrono-amperometric process for $\mathrm{Py} / \mathrm{Py}-\mathrm{COOH} / \mathrm{MNPs}$ electrodeposition. During this step it was interesting to specify that the amplitude of the charge-discharge process remains nearly unchanged, indicating that the electrode surface displays homogenous $\mathrm{Py} / \mathrm{Py}-\mathrm{COOH} / \mathrm{MNPs}$ layer. $\mathrm{CV}$ analysis were also investigated to examine the behavior of the $\mu \mathrm{WEs}$ surfaces after Py/Py-COOH/MNPs electrodeposition. Fig. S1D (Supplementary information) shows the considerable increase in the peak current of cyclic voltammograms after $\mathrm{Py} / \mathrm{Py}-\mathrm{COOH} / \mathrm{MNPs}$ deposition compared to bare gold. This was explained by the conductive behavior of Py/Py-COOH coated on MNPs. At these steps, the modified gold $\mu$ WEs were ready for bio-functionalization with the target analyte.

\subsection{Optimization of conditions for detection}

The amount of TC immobilized on the surface of gold $\mu$ WEs as well as the antibody concentration were subject to optimization described in (Supplementary information).

\subsection{Competitive detection of TC}

In this study, the quantification of the analyte has been made by the competitive approach to enhance the detection signal of TC with a small molecular weight (444 Da) compared to Ab-TC (160 kDa). Furthermore, this approach was advantaged in the present work to make pre-concentration allowing to detect only TC and eliminate other irrelevant molecules. This step was performed by incubating the $\mu \mathrm{WE}$ surfaces of the Bio-MEMS in a mixture of a fixed concentration of Ab-TC previously optimized $\left(10 \mu \mathrm{g} . \mathrm{mL}^{-1}\right)$ and decreasing levels of standard solutions of TC from $1000 \mathrm{pg} \cdot \mathrm{mL}^{-1}$ to $0.1 \mathrm{pg} \cdot \mathrm{mL}^{-1}$ during $30 \mathrm{~min}$ at $4{ }^{\circ} \mathrm{C}$ for each concentration. At least three independents replicated experiments were carried out. Ultimately, the electrode surface was rinsed with PBST (10 mM PBS with $0.05 \%$ Tween 20) and analyzed with EIS. Fig. 4A-C show the obtained Nyquist plot semi-circles for the three functionalizations of $\mu \mathrm{WE}$ surfaces. It can be noticed that for the three approaches, the Nyquist plot semi-circles increase by decreasing TC concentrations. As awaited, this level decreases produce an increase in the charge transfer resistance owed to the presence of free antibodies reacting with TC immobilized on the $\mu$ WEs surface.

An excellent fitting between the simulated and experimental spectra was obtained for each TC concentration by using the Randles equivalent circuit shown in the inset of Fig. 4D (where $\mathrm{R}_{\mathrm{s}}$ is the solution resistance, $\mathrm{R}_{\mathrm{ct}}$ is the charge-transfer resistance, $\mathrm{W}$ is the Warburg impedance and $\mathrm{Q}$ is the constant phase element). For each TC concentration, the value of $\Delta \mathrm{R} / \mathrm{R}_{0}$ was calculated when $\mathrm{R}$ is the charge transfer resistance. The normalized data show three linear equations: $\mathrm{y}_{\mathrm{a}}=-0.208 \mathrm{x}+0.960, \mathrm{y}_{\mathrm{b}}=-0.148 \mathrm{x}+0.578$ and $\mathrm{y}_{\mathrm{c}}=-0.109 \mathrm{x}+0.474$ with the determination coefficients of $0.962,0.986$ and 0.946 , respectively. As can be seen from this figure, the detection sensitivity was highly improved for the Py/Py-COOH/MNPs gold surface modification. For this approach, the configured impedimetric immunosensor have provided the more sensitivity of $0.208 \mathrm{~mL} \cdot \mathrm{pg}^{-1}$ with a limit of detection (LOD) of 1.2 pg.mL $\mathrm{m}^{-1}$. It is appealing to notice that this LOD value is nearly 83000 times lower than the 
maximum residue limits of TC in honey fixed by European regulation. As listed in Table 1, the proposed system provides relatively wide linear ranges and low LODs in comparison with other published studies.
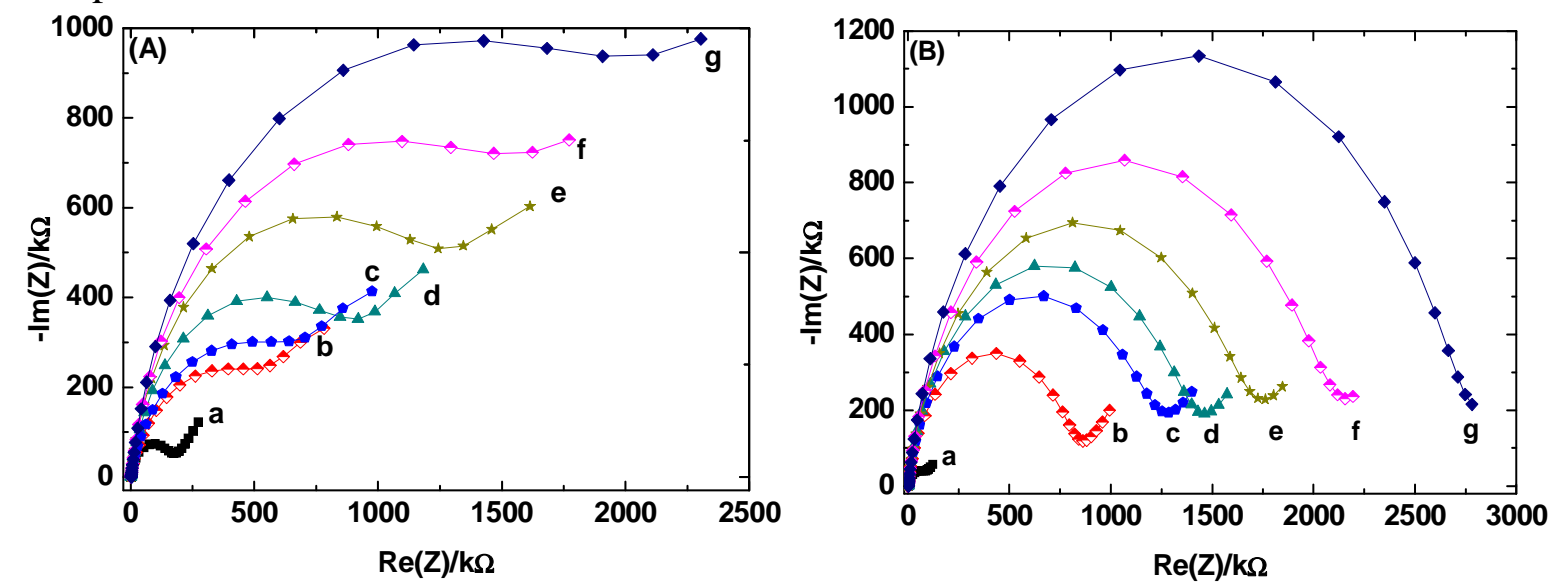

309
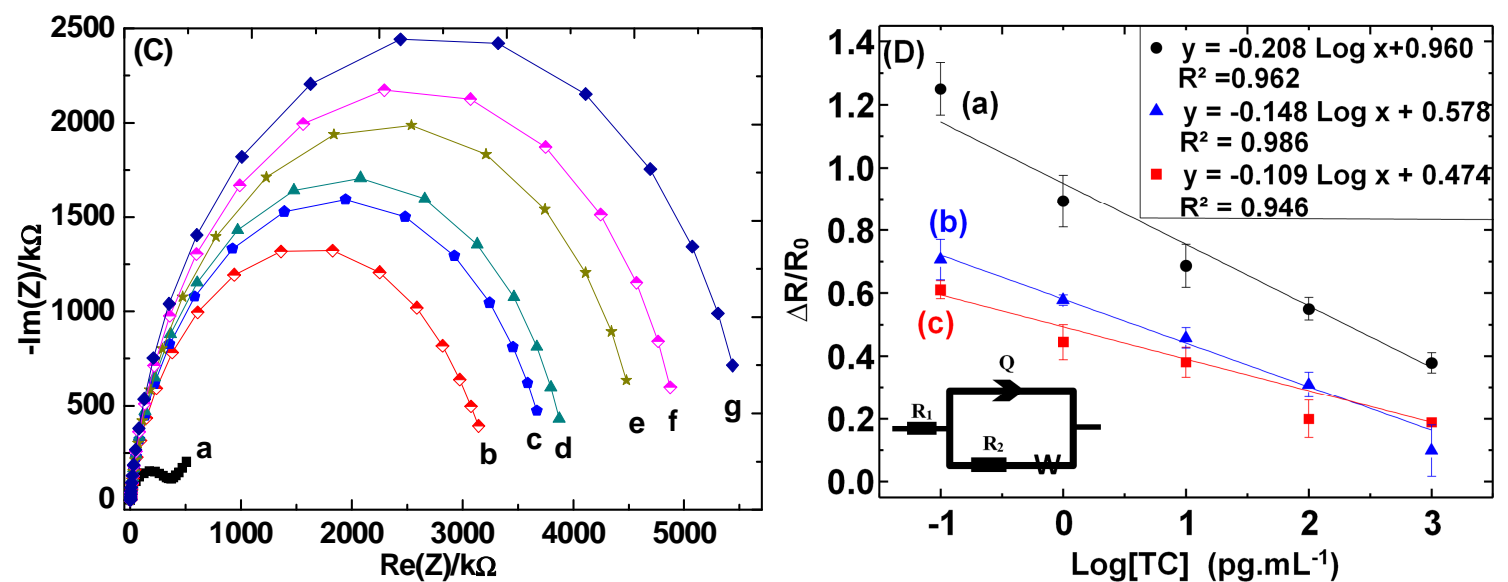

Fig. 4. Nyquist impedance plots in $5 \mathrm{mM}$ of $\left[\mathrm{Fe}(\mathrm{CN})_{6}\right]^{3-/ 4-}$ for competitive detection of $\mathrm{TC}$ on the modified $\mu$ WEs by: (A) Functionalization with CMA, (B) Functionalization with CMA followed by preconcentration step, (C) Functionalization with Py/Py-COOH/MNPs, where (a) Bare gold, (b) After TC immobilization at $100 \mu \mathrm{g} \cdot \mathrm{mL}^{-1}$, (c-g) After competitive detection of TC at 1000,100,10,1 and 0,1 pg.mL ${ }^{-1}$, respectively. (D) The sensitivity of the immunosensor by normalization of Nyquist plot data, inset: the equivalent circuit used for EIS fitting.

Table 1. Comparison of different techniques for TC detection.

\begin{tabular}{|c|c|c|c|c|}
\hline Methods & $\begin{array}{c}\text { Linear range } \\
\left(\text { (ng.mL }{ }^{-1}\right)\end{array}$ & LOD (ng.mL $\left.{ }^{-1}\right)$ & $\begin{array}{c}\text { Real } \\
\text { sample }\end{array}$ & References \\
\hline $\begin{array}{l}\text { High-performance liquid- } \\
\text { chromatography with } \\
\text { fluorescence detection }\end{array}$ & $15-5000$ & 5 & Milk & $\begin{array}{l}\text { (Kargin et } \\
\text { al., 2016) }\end{array}$ \\
\hline $\begin{array}{l}\text { Photoelectrochemical } \\
\text { aptasensor }\end{array}$ & $0.2-1000.0$ & 0.01 & $\begin{array}{c}\text { Drug } \\
\text { sample }\end{array}$ & $\begin{array}{l}\text { (Han et al., } \\
\text { 2018) }\end{array}$ \\
\hline Terahertz spectroscopy & $0-20 \times 106$ & 0.45 & $\begin{array}{l}\text { Water } \\
\text { and }\end{array}$ & $\begin{array}{c}\text { (Qin et al., } \\
\text { 2017) }\end{array}$ \\
\hline
\end{tabular}


milk

\begin{tabular}{|c|c|c|c|c|}
\hline $\begin{array}{l}\text { Enzyme-linked } \\
\text { immunosorbent assay and } \\
\text { immunochromatographic assay }\end{array}$ & $0.26-2.00$ & 15 & $\begin{array}{l}\text { Milk } \\
\text { and } \\
\text { honey }\end{array}$ & $\begin{array}{c}\text { (Chen et al., } \\
\text { 2016) }\end{array}$ \\
\hline Electrochemical immunoassay & $0.05-100$ & 0.006 & $\begin{array}{l}\text { Honey } \\
\text { milk } \\
\text { and } \\
\text { peanuts }\end{array}$ & $\begin{array}{c}\text { (Que et al., } \\
\text { 2013) }\end{array}$ \\
\hline $\begin{array}{l}\text { Molecularly imprinted } \\
\text { polymer mixed with solid- } \\
\text { phase extraction }\end{array}$ & $20-600$ & 20 & Milk & $\begin{array}{l}\text { (Xie et al., } \\
\text { 2018) }\end{array}$ \\
\hline $\begin{array}{l}\text { Electrochemical } \\
\text { immunosensor based on the } \\
\text { chitosan-magnetic } \\
\text { nanoparticles }\end{array}$ & $0.08-1.00$ & 0.03 & Milk & $\begin{array}{c}\text { (Liu et al., } \\
2016)\end{array}$ \\
\hline Amperometric immunosensor & $0.0005-500$ & 0.86 & Milk & $\begin{array}{l}\text { (Conzuelo et } \\
\text { al., 2013) }\end{array}$ \\
\hline This work & 0.0001-1 & 0.0012 & Honey & - \\
\hline
\end{tabular}

\subsection{Interferences study}

The selectivity of the proposed system was investigated in the presence of various antibiotics from the same family of cyclines that can have cross-reactivity with Ab-TC antibody. This study was performed by comparing the responses for TC detection with three analogous molecules namely: chlortetracycline (CT), doxycycline (DX), and oxytetracycline (OX) (Fig. S3) (Supplementary information). Consequently, this immunosensor was found to be very selective for TC and can provide reliable results regardless of the presence of the interfering molecules.

\subsection{Analysis of spiked honey samples}

The TC determination in real samples was performed by spiking analyte in blank honey matrices which indicate that the calibration curve is suitable to determine the TC content in real unknown samples (Supplementary information). The results of the added spiked samples are shown in Table S1 (Supplementary information). Good recoveries from $80 \%$ to $98 \%$ were obtained with the RSD ranging between $1 \%$ and $6 \%$, which indicate that the calibration curve is suitable to determine the TC content in real unknown samples.

\subsection{Detection of TC in unknown honey sample}

The standard addition method was further employed to determine the TC concentration in unknown honey sample. The competitive detection of TC was performed by a mixture of different standard solutions $\left(3 \mathrm{pg} \cdot \mathrm{mL}^{-1}, 5\right.$ pg.mL $\mathrm{mL}^{-1}, 10$ pg.mL $\left.\mathrm{L}^{-1}, 15 \mathrm{pg} \cdot \mathrm{mL}^{-1}\right)$ with the presence of Ab-TC $\left(10 \mu \mathrm{g} \cdot \mathrm{mL}^{-1}\right)$. For all TC concentrations, the normalized charge transfer resistance $\Delta \mathrm{R} / \mathrm{R}_{0}$ were measured. The extrapolation of regression line predicts the TC concentration in the diluted honey sample at $2.52 \mathrm{pg} \cdot \mathrm{mL}^{-1}$. Consequently, the concentration of TC in the unknown sample was $25.2 \mathrm{pg} . \mathrm{mL}^{-1}$ according to the dilution factor of 10 times (Fig. 5). This level of contamination remains lower than the MRLs of 10 000 pg. $\mathrm{mL}^{-1}$ established by Switzerland, UK, and Belgium. 


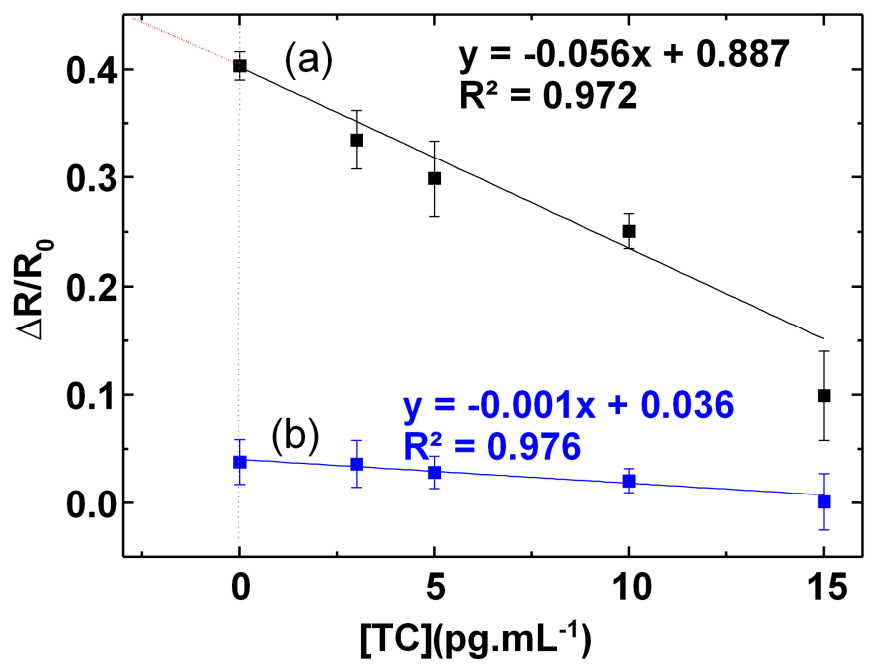

Fig. 5. Standard addition plots of different TC spiking in diluted unknown honey sample, using (a) Ab-TC and (b) Ab-155 antibodies.

\section{Conclusions}

In the present work, we have discussed the development process of a novel sensitive and highly selective immunosensor based on 2D and 3D network of immobilization with the diazonium salt, and a new structure of MNPs coated with $\mathrm{Py}-\mathrm{COOH}$ for specific detection of TC. Moreover, the electrochemical analysis performed by these materials allow high reproducibility and rapid response. The high sensitivity of this immunosensor was evaluated for the three functionalization methods and was highly improved for the Py/Py$\mathrm{COOH} / \mathrm{MNPs}$ gold surface modification. For this approach, the configured impedimetric immunosensor have provided a sensitivity of $0.208 \mathrm{~mL} \cdot \mathrm{pg}^{-1}$ with a limit of detection of 1.2 pg. $\mathrm{mL}^{-1}$. The selectivity of the present immunosensor platform toward TC was higher when compared to analogous molecules, namely DX, CT and OX. We have presented a novel and less costly fabrication process to develop a highly sensing device able to detect low levels of TC residues in honey samples without any complicated pretreatment. The miniaturization of this immunosensor will be very beneficial to control the quality of food products on an industrial scale. However, there are still some limitations of this work related to the construction time which is a little long. Therefore, our further investigations in this direction are to shorten the development time of this immunosensor, to meet the requirements of a large scientific community which can extend its use for other applications. Future works will also be done, to assess the multi-functionalization of the same device allowing a simultaneous detection of several analytes.

\section{Acknowledgements}

The authors acknowledge the financial support from PHC-Toubkal under the project No.32567YD, and funding from the European Union's Horizon 2020 research and innovation programme entitled HEARTEN under grant agreement No 643694" and microMole grant agreement No 643694 and No 653626, respectively.

\section{References}

Baraket, A., Lee, M., Zine, N., Sigaud, M., Yaakoubi, N., Trivella, M.G., Zabala, M., Bausells, J., Jaffrezic-Renault, N., Errachid, A., 2013. Diazonium modified gold microelectrodes onto polyimide substrates for impedimetric cytokine detection with an integrated $\mathrm{Ag} / \mathrm{AgCl}$ reference electrode. Sensors and Actuators B: Chemical 189, 165172. 
Bargańska, Ż., Namieśnik, J., Ślebioda, M., 2011. Determination of antibiotic residues in honey. TrAC Trends in Analytical Chemistry 30, 1035-1041.

Bougrini, M., Florea, A., Cristea, C., Sandulescu, R., Vocanson, F., Errachid, A., Bouchikhi, B., El Bari, N., Jaffrezic-Renault, N., 2016. Development of a novel sensitive molecularly imprinted polymer sensor based on electropolymerization of a microporous-metal-organic framework for tetracycline detection in honey. Food Control 59, 424-429.

Chen, Y., Kong, D., Liu, L., Song, S., Kuang, H., Xu, C., 2016. Development of an ELISA and immunochromatographic assay for tetracycline, oxytetracycline, and chlortetracycline residues in milk and honey based on the class-specific monoclonal antibody. Food Analytical Methods 9, 905-914.

Chopra, I., Roberts, M., 2001. Tetracycline antibiotics: mode of action, applications, molecular biology, and epidemiology of bacterial resistance. Microbiology and molecular biology reviews 65, 232-260.

Conzuelo, F., Campuzano, S., Gamella, M., Pinacho, D.G., Reviejo, A.J., Marco, M.P., Pingarrón, J.M., 2013. Integrated disposable electrochemical immunosensors for the simultaneous determination of sulfonamide and tetracycline antibiotics residues in milk. Biosensors and Bioelectronics 50, 100-105.

Deng, B., Xu, Q., Lu, H., Ye, L., Wang, Y., 2012. Pharmacokinetics and residues of tetracycline in crucian carp muscle using capillary electrophoresis on-line coupled with electrochemiluminescence detection. Food Chemistry 134, 2350-2354.

Desmarchelier, A., Anizan, S., Minh Tien, M., Savoy, M.-C., Bion, C., 2018. Determination of five tetracyclines and their epimers by LC-MS/MS based on a liquid-liquid extraction with low temperature partitioning. Food Additives \& Contaminants: Part A.

Economou, V., Gousia, P., 2015. Agriculture and food animals as a source of antimicrobialresistant bacteria. Infection and drug resistance 8, 49.

Eliopoulos, G.M., Eliopoulos, G.M., Roberts, M.C., 2003. Tetracycline therapy: update. Clinical infectious diseases 36, 462-467.

European Commission, 1999. European Commission (1999) Off J Eur Union L 60:16-52.

Gaurav, A., Gill, J.P.S., Aulakh, R.S., Bedi, J.S., 2014. ELISA based monitoring and analysis of tetracycline residues in cattle milk in various districts of Punjab. Veterinary World 7.

Han, Q., Wang, R., Xing, B., Chi, H., Wu, D., Wei, Q., 2018. Label-free photoelectrochemical aptasensor for tetracycline detection based on cerium doped $\mathrm{CdS}$ sensitized BiYWO 6. Biosensors and Bioelectronics 106, 7-13

Hassani, N.E.A.E., Baraket, A., Neto, E.T.T., Lee, M., Salvador, J.-P., Marco, M., Bausells, J., Bari, N.E., Bouchikhi, B., Elaissari, A., Errachid, A., Zine, N., 2017. Novel strategy for sulfapyridine detection using a fully integrated electrochemical Bio-MEMS: Application to honey analysis. Biosensors and Bioelectronics 93, 282-288.

Joshi, M.D., Anderson, J.L., 2012. Recent advances of ionic liquids in separation science and mass spectrometry. Rsc Advances 2, 5470-5484.

Kargin, I.D., Sokolova, L.S., Pirogov, A.V., Shpigun, O.A., 2016. HPLC determination of tetracycline antibiotics in milk with post-column derivatization and fluorescence detection. Inorganic Materials 52, 1365-1369.

Kivrak, I., KIVRAK, Ş., Harmandar, M., 2016. Development of a rapid method for the determination of antibiotic residues in honey using UPLC-ESI-MS/MS. Food Science and Technology (Campinas) 36, 90-96.

Lan, L., Yao, Y., Ping, J., Ying, Y., 2017. Recent advances in nanomaterial-based biosensors for antibiotics detection. Biosensors and Bioelectronics 91, 504-514.

Liu, X., Zheng, S., Hu, Y., Li, Z., Luo, F., He, Z., 2016. Electrochemical immunosensor based on the chitosan-magnetic nanoparticles for detection of tetracycline. Food Analytical Methods 9, 2972-2978. 
Lv, Y.-K., Zhang, J.-Q., He, Y.-D., Zhang, J., Sun, H.-W., 2014. Adsorption-controlled preparation of molecularly imprinted hybrid composites for selective extraction of tetracycline residues from honey and milk. New Journal of Chemistry 38, 802-808.

Majdinasab, M., Yaqub, M., Rahim, A., Catanante, G., Hayat, A., Marty, J.L., 2017. An Overview on Recent Progress in Electrochemical Biosensors for Antimicrobial Drug Residues in Animal-Derived Food. Sensors 17, 1947.

Mitra, S., 2004. Sample Preparation Techniques in Analytical Chemistry. John Wiley \& Sons.

Nelson, M.L., Dinardo, A., Hochberg, J., Armelagos, G.J., 2010. Brief communication: mass spectroscopic characterization of tetracycline in the skeletal remains of an ancient population from Sudanese Nubia 350-550 CE. American journal of physical anthropology 143, 151-154.

O'Connor, S., Aga, D.S., 2007. Analysis of tetracycline antibiotics in soil: advances in extraction, clean-up, and quantification. TrAC Trends in Analytical Chemistry 26, 456465.

Pokrant, E.V., Maddaleno, A.E., Araya, C.E., San Martínb, B.V., Cornejo, J., 2018. In-House Validation of HPLC-MS/MS Methods for Detection and Quantification of Tetracyclines in Edible Tissues and Feathers of Broiler Chickens. J. Braz. Chem. Soc 29, 659-668.

Qin, J., Xie, L., Ying, Y., 2017. Rapid analysis of tetracycline hydrochloride solution by attenuated total reflection terahertz time-domain spectroscopy. Food chemistry 224, 262 269.

Qin, J., Xie, L., Ying, Y., 2016. A high-sensitivity terahertz spectroscopy technology for tetracycline hydrochloride detection using metamaterials. Food chemistry 211, 300-305.

Que, X., Chen, X., Fu, L., Lai, W., Zhuang, J., Chen, G., Tang, D., 2013. Platinum-catalyzed hydrogen evolution reaction for sensitive electrochemical immunoassay of tetracycline residues. Journal of Electroanalytical Chemistry 704, 111-117.

Shi, X., Meng, Y., Liu, J., Sun, A., Li, D., Yao, C., Lu, Y., Chen, J., 2011. Group-selective molecularly imprinted polymer solid-phase extraction for the simultaneous determination of six sulfonamides in aquaculture products. Journal of Chromatography B 879, 10711076.

Tang, Y., Zhang, J., Liu, J.-H., Gapparov, I., Wang, S., Dong, Y., Su, H., Tan, T., 2017. The development of a graphene oxide-based aptasensor used for the detection of tetracycline in honey. Analytical Methods 9, 1133-1140.

Tenório-Neto, E.T., Baraket, A., Kabbaj, D., Zine, N., Errachid, A., Fessi, H., Kunita, M.H., Elaissari, A., 2016. Submicron magnetic core conducting polypyrrole polymer shell: Preparation and characterization. Materials Science and Engineering: C 61, 688-694.

Wang, S., Liu, J., Yong, W., Chen, Q., Zhang, L., Dong, Y., Su, H., Tan, T., 2015. A direct competitive assay-based aptasensor for sensitive determination of tetracycline residue in honey. Talanta 131, 562-569.

Wang, S., Yong, W., Liu, J., Zhang, L., Chen, Q., Dong, Y., 2014. Development of an indirect competitive assay-based aptasensor for highly sensitive detection of tetracycline residue in honey. Biosensors and Bioelectronics 57, 192-198.

Xie, Y., Hu, Q., Zhao, M., Cheng, Y., Guo, Y., Qian, H., Yao, W., 2018. Simultaneous Determination of Erythromycin, Tetracycline, and Chloramphenicol Residue in Raw Milk by Molecularly Imprinted Polymer Mixed with Solid-Phase Extraction. Food Analytical Methods 11, 374-381.

Yi, X., Li, L., Peng, Y., Guo, L., 2014. A universal electrochemical sensing system for small biomolecules using target-mediated sticky ends-based ligation-rolling circle amplification. Biosensors and Bioelectronics 57, 103-109. 